Article

\title{
Sustainable Manufacturing Practices, Competitive Capabilities, and Sustainable Performance: Moderating Role of Environmental Regulations
}

\author{
Hazem Ali $\mathbb{B}^{\text {, Ting Chen }}{ }^{*}$ and Yunhong Hao \\ School of Business Administration, Zhejiang Gongshang University, Hangzhou 310018, China; \\ yahyahazem2025@gmail.com (H.A.); haoyh@zjgsu.edu.cn (Y.H.) \\ * Correspondence: gaby@mail.zjgsu.edu.cn
}

Citation: Ali, H.; Chen, T.; Hao, Y. Sustainable Manufacturing Practices, Competitive Capabilities, and Sustainable Performance: Moderating Role of Environmental Regulations. Sustainability 2021, 13, 10051.

https://doi.org/10.3390/su131810051

Academic Editors: Francesca Gennari, Raffaella Cassano and Fabio La Rosa

Received: 31 July 2021

Accepted: 1 September 2021

Published: 8 September 2021

Publisher's Note: MDPI stays neutral with regard to jurisdictional claims in published maps and institutional affiliations.

Copyright: (c) 2021 by the authors. Licensee MDPI, Basel, Switzerland. This article is an open access article distributed under the terms and conditions of the Creative Commons Attribution (CC BY) license (https:// creativecommons.org/licenses/by/ $4.0 /)$.

\begin{abstract}
Research highlights the increasing engagement of SMEs in adopting sustainable practices to enhance their sustainable performance. This paper extends the current literature on sustainable manufacturing practices (SMPs) and SMEs' sustainable performance by examining the mediating effect of competitive capabilities and the moderating impact of environmental regulation. Structured questionnaires were used to collect data from 288 manufacturing SMEs in China. Research findings using structural equation modeling with partial least squares (PLS-SEM) revealed that adopting SMPs enables SMEs to gain competitive capabilities and to positively influence their sustainable performance. In addition, gaining competitive capabilities have a positive mediating impact on the relationship between SMPs and SMEs' sustainable performance. Further, the interaction between SMPs and environmental regulation strengthens SMEs' sustainable performance. At the end of this paper, a set of concluding remarks and implications is drawn.
\end{abstract}

Keywords: sustainable manufacturing practices; competitive capabilities; sustainable performance; environmental regulations; SMEs

\section{Introduction}

Sustainability in manufacturing has gained wide recognition in recent years with more calls for manufacturers to ensure preserving the environment and social alleviation besides economic growth. Sustainable development is essential to cope with environmental problems (e.g., climate change and pollution) caused by the rapid pursuit of economic growth [1] and requires joint efforts from several parties, particularly governments and business organizations [2]. The sustainability concept emphasizes businesses' social and environmental contributions to society while maintaining financial profitability as well [3]. Aboelmaged [4] indicated that research on sustainability is divided into two main streams, green manufacturing and sustainable manufacturing, and argued for sustainability manufacturing. This study focuses on the second research stream and advocates its importance in contributing to sustainability adoption, particularly within the manufacturing SMEs context. In addition, this research responds to Agan et al.'s [5] call for more research on SMPs and performance benefits for SMEs and Chen et al.'s [6] call to remove the ambiguity about SMEs' knowledge of identifying the ways of achieving sustainable improvement while considering their limited financial, technological, and human resources.

Sustainable manufacturing was defined as "the creation of manufactured products that use processes that minimize negative environmental impacts, conserve energy and natural resources, are safe for employees, communities, and consumers and are economically sound" [7]. This study builds on Garetti and Taisch's [8] definition of sustainable manufacturing as the firm's ability to maintain the intelligent use of natural resources to fulfill economic, social, and environmental aspects, which eventually leads to improving quality of life and preserving the environment. Recognizing the fact that $20 \%$ of global 
carbon dioxide emission is generated by the manufacturing of goods, sustainable manufacturing is advocated to increase sustainability awareness and provide a huge contribution to global GDP [9]. As an emergent field, sustainable manufacturing has gained increasing attention from academicians and policymakers during the last decade [4], which replaces traditional operating practices with innovative processes that consider economic, social, and environmental effects [10]. Prior research on sustainable manufacturing identified the four "Rs" strategies: reduce, remanufacture, recycle, and reuse as the fundamental cornerstones of environmentally conscious manufacturing [11] and determining good SMPs [12]. Garetti et al. [8] argued that sustainable manufacturing ensures that operational processes, starting from the product design phase to packaging and delivery to the consumer phase, consider the efficient consumption of natural resources and the interests of stakeholders.

Researchers highlighted the neglecting of some environmental concerns such as water contamination and waste recycling [13] and emerging types of pollution such as face masks produced by large-scale manufacturing [14]. China's economic growth since 1978 was accompanied with the huge consumption of natural resources and high environmental costs [15]. China's quick economic recovery from COVID-19 has provided a vast yet narrow opportunity to build a clean, safe, and fair economy [16]. In addressing climate change, $\mathrm{Li}$ et al. [17] argued that Chinese manufacturing has undertaken the responsibility of energy conservation and emission reduction.

Behjati [18] reported that $64 \%$ of air pollution is generated by manufacturing SMEs, and only 0.4 of these SMEs adhere to environmental protection. Global industrialization forces SMEs to adhere to environmental regulations and responsibilities to adopt sustainable manufacturing, which results in generating less waste [19]. Khan, Sisi, and Siqun [20] argued that governments can develop and implement relevant environmental regulations to decrease the negative impact of manufacturing organizations on the environment and normalize their economic behavior. Governments, nongovernmental organizations, and customers undertake an increasing role in forcing SMEs to adopt sustainability [21]. Zailani et al. [22] stated that due to social issues and global warming, regulatory agencies and stakeholders play a significant role in forcing manufacturing firms to adopt sustainability. Firms have increased their awareness of competitive advantages that can be gained from sustainable performance due to stakeholders' increasing demand for firms' social and environmental responsibility [23]. Many countries are striving to achieve the United Nations' 2030 sustainable development goals through developing and implementing relevant regulations [24]. Therefore, it is essential to ensure manufacturing SMEs' involvement in adopting favorable environmental manufacturing practices in their process and business strategy and to adhere to relevant environmental laws and regulations.

Overall, this study aims to examine the relationship between SMPs and SMEs' sustainable performance and to examine the indirect mediating effect of competitive capabilities and moderating impact of environmental regulation. The subsequent sections of this paper are organized as follows: Section 2 introduces the underlying theory guiding this research, an extensive review and synthesis of the relevant literature, and the development of research hypotheses. Section 3 explains the methodological perspectives followed to undertake this study and to test the hypothetical relationships among the study variables. Section 4 presents the results of the study, while Section 5 presents the research findings and compares them with the current literature. Finally, Section 6 provides the concluding remarks, limitations of this research, and implications and proposes some promising research avenues.

\section{Literature Review and Hypothesis}

This study builds on the firm's natural-resource-based view (NRBV) developed by Hart [25] as an extension to the resource-based view which emphasizes the influential role of organizational resources and capabilities in gaining and sustaining competitive advantages. NRBV argues that firms can gain competitive advantages when interacting with their natural environment through sustainable development [25]. For instance, de- 
creasing wastes and preventing pollutants can lead to decreasing manufacturing costs and enhancing efficiency. Further, NRBV pays increasing attention to pressures maintained by stakeholders and calls for integrating such pressures with organizational processes and strategies to achieve sustainable development. Many researchers have employed the NRBV within the SMEs context. For example, Aragon-Correa et al. [26] reported that stakeholder management, strategic proactivity, and shared vision capabilities were positively related to Spanish SMEs' environmental leadership, adherence to environmental regulations, and pollution prevention, which enhanced their financial performance, while Woo et al. [27] highlighted that labor productivity can be enhanced through adopting environmental innovation in SMEs' business strategy.

Research on sustainability focused mainly on large enterprises with little attention paid to examining SMEs' sustainable performance $[28,29]$. The involvement of SMEs in advancing sustainable development goals determined by the United Nations is essential due to their fundamental impact on economic, social, and environmental perspectives [24]. The majority of studies undertaken to examine SMEs' sustainability focused on the influence of green, lean, innovation, and other enablers of sustainable performance or identifying the drivers and barriers of implementing sustainability [30]. Prieto-Sandoval et al. [31] highlighted the need for more research on the relationship between the circular economy implementation and SMEs sustainable development. While manufacturing SMEs contributes significantly to national GDP, they cause negative impacts on the environment due to avoiding environmentally sustainable practices in their strategies and processes [32].

Researchers highlighted the impact of adopting SMPs and of enhancing economic, social, and environmental performance. Afum et al. and Hong et al. indicated a positive relationship between sustainable practices and firms' sustainable performance [33,34]. Firms can promote and improve their image before stakeholders through adopting favorable environmental practices [35]. Organizational social performance is extended from its corporate social responsibility initiative and refers to the actual achievement in maintaining and improving the quality besides enhancing environmental protection [29]. According to Zailani et al. [36], firms' environmentally friendly practices such as packaging and waste reduction have a positive impact on their social performance through providing ecoproducts, motivating the involvement of nongovernmental organizations in organizational sustainable activities, and increasing public awareness toward sustainability.

Saqib and Zhang [37] indicated that sustainable practices of manufacturing, procurement, and distribution are significantly related to a firm's sustainability performance. Similarly, Abdul-Rashid et al. [38] found that a sustainable manufacturing process is positively related to sustainability performance in the Malaysian manufacturing sector. However, Habidin et al. [39] argued that only fewer SMPs serve as predictors of SMEs' environmental performance in the Malaysian automotive industry. Firms' environmental performance is positively affected by adopting manufacturing practices that aim to manage carbon dioxide emissions, wastes, and pollutants and reduce energy consumption. Operational outcomes gained from SMPs involve cost reduction, improving production flexibility, accelerating product delivery, and improving product quality [40,41]. Li et al. [17] underlined that Chinese intensive energy-based firm's social performance is positively related to recycling, while green product innovation positively influenced financial performance.

Sroufe [42] found that environmentally based design practices such as the high usage of recycled materials and those that are designed to reduce $\mathrm{CO} 2$ emissions and disassembly significantly reduce costs and increase firms' market share. The extant literature established a positive relationship between favorable environmental practices during the manufacturing process (e.g., controlling emissions, waste reduction, effective management of disposals and pollutants, and decreasing energy consumption) and the firm's profitability [43-45].

Sustainable practices used to reflect the solution of sustainability issues involve sustainable manufacturing, sustainable procurement, and sustainable distribution [46]. This study builds on the adoption of sustainable manufacturing among Chinese SMEs and its impact on their sustainable performance. The major SMPs involve the implementation of 
the 3Rs, minimizing waste, reducing the generation of hazardous substances, and ensuring an efficient use of energy [47]. In a similar vein, Chin et al. [48] depicted SMPs as the process of reducing, reusing, and recycling resources and collaborating to recover the components of a product, while minimizing resources consumption during the manufacturing process. Many researchers underlined that SMPs are vital for enhancing a company's sustainable performance [49-51]. In this vein, Yildiz et al. [46] argued that SMPs play an influential role in improving firms' sustainable performance. Accordingly, the first research hypothesis is set as follows:

Hypothesis 1 (H1). SMPs positively influence SMEs' sustainable performance.

Firms maintaining competitive capabilities such as innovation, quality, cost, flexibility, and efficiency can provide distinctive customer value and outperform their competitors. This study builds on four competitive dimensions in operations research: quality, flexibility, cost, and delivery [52]. Manufacturing companies who maintain such capabilities can achieve customer satisfaction through providing goods and services at a lower cost, with fast delivery, with qualified products, and by responding to changing customers and market needs. Former research undertaken by Porter and van der Linde [53] underlined that adopting green practices allows firms to reduce resource consumption, utilize byproducts efficiently, reduce downtime, maintain a safer workplace, reduce product and operation handling costs, provide qualified products, and increase scrap value. In this regard, Bhardwaj [54] argued that enhancements in managing processes and product manufacturing lead to increasing production flexibility and accelerating product delivery to consumers. Aboelmaged [4] indicated a positive relationship between SMPs and competitive capabilities (quality, cost, delivery, and flexibility).

SMPs minimize manufacturing costs, provide valuable products, and respond to social and environmental concerns [55]. In addition, SMPs improve operational processes to produce high-quality products that satisfy customers and increase a firm's market share [56]. Ramayah et al. [57] underlined that SMPs such as reducing solid waste enhance Malaysian SMEs' competitive performance. Sezen and Çankaya [58] found that firms' operational performance was positively related to green manufacturing applications through ensuring occupational safety, enhancing production efficiency, and minimizing manufacturing costs in the Turkish manufacturing sector. Agan et al. [5] argued that firms can boost their competitive advantages and increase their profit in the long run through the adoption of SMPs. Further, SMPs improve operational efficiency, which, in turn, enhances the firm's long-term profitability, reduce production cost [53], and improve the quality and delivery of products and enhance production flexibility [40]. Thus, this study predicts a significant association between SMPs and sustainable performance of manufacturing SMEs and intends to examine the following hypotheses:

Hypothesis 2a (H2a). SMPs have a positive impact on product cost.

Hypothesis $\mathbf{2 b}(\mathbf{H} \mathbf{2 b})$. SMPs have a positive impact on production flexibility.

Hypothesis $2 \mathbf{c}(\mathbf{H} 2 \mathbf{c})$. SMPs have a positive impact on product quality.

Hypothesis $\mathbf{2 d}(\mathbf{H} \mathbf{2 d})$. SMPs have a positive impact on product delivery.

Firms need to gain relevant competitive advantages to survive and maintain distinctive performance. This study predicts that undertaking SMPs enables manufacturing SMEs to gain competitive advantages and maintain superior sustainable performance. In his research on linking SMEs' business models and performance, Anwar [59] indicated that competitive advantages had a positive mediating influence. Wu and Pagell [60] indicated that adopting environmental practices allows SMEs to maintain operational efficiencies, which in turn, enhances their financial performance [61]. Firms undertaking sustainability 
practices can gain competitive advantages and enter new markets [62], maintain strong social relations with employees $[63,64]$, and increase their customer base and maintain a positive brand image [65].

Gadenne et al. [66] found that cost-saving intentions are the fundamental reasons behind SMEs' adoption of sustainable practices, while Sáez-Martínez et al. [67] found that the strategic intention of SMEs leads to undertaking environmental responsibility. SMEs have limited knowledge of sustainability practices due to some internal factors such as organizational culture and external factors including suppliers and customers ([68]). Kozlowski et al. established that recycling practices allow firms to avoid reducing wastes and pollutants through minimizing the usage of new raw materials and energy consumption [69].

Eslami et al. [70] advocated that manufacturing firms need to adopt sustainable practices to meet emerging customers' needs for sustainable products and to adhere to environmental regulations. Manufacturing firms face several challenges to adopting sustainable manufacturing such as environmental regulations, resources depletion, and pressures from customers and nongovernmental organizations. Jawahir et al. [71] stressed the need for more research on sustainable manufacturing and found that it reduces unfavorable environmental impact through improving resource and energy efficiency, generating a minimum quality of waste, providing a safer work climate, and maintaining high-quality products at affordable costs. SMEs' performance is positively related to pursuing competitive strategy and maintaining competitive advantages [72,73]. Based on these argumentations, the following hypothesis predicts that competitive capabilities have a positive significant mediating impact on the relationship between SMPs and SMEs' sustainable performance and is stated as follows:

Hypothesis 3a (H3a). Product cost capabilities mediate the relationship between SMP and sustainable performance.

Hypothesis $\mathbf{3 b} \mathbf{( H 3 b ) . ~ P r o d u c t i o n ~ f l e x i b i l i t y ~ c a p a b i l i t i e s ~ m e d i a t e ~ t h e ~ r e l a t i o n s h i p ~ b e t w e e n ~ S M P ~}$ and sustainable performance.

Hypothesis 3c $\mathbf{( H 3 c ) . ~ P r o d u c t ~ q u a l i t y ~ c a p a b i l i t i e s ~ m e d i a t e ~ t h e ~ r e l a t i o n s h i p ~ b e t w e e n ~ S M P ~ a n d ~}$ sustainable performance.

Hypothesis 3d (H3d). Product delivery capabilities mediate the relationship between SMP and sustainable performance.

Environmental regulations have emerged in many countries to guide sustainability processes and policies and to shape firms' sustainable behaviors and actions. Many countries have developed different levels of environmental regulations to stimulate manufacturers' interest in adopting SMPs. Environmental regulations issued by the government present some restrictions on the manufacturing process to ensure resource utilization, clean production, and social responsibilities. Shankar et al. [74] and Mittal and Sangwan [75] underlined that imminent environmental legislations have resulted in clean production and efficient resource utilization in the manufacturing process in Indian and Malaysian manufacturing organizations. In his research on the drivers of sustainable manufacturing, Aboelmaged [4] reported that environmental regulations do not affect SMPs.

Research revealed that compliance with environmental regulations of using clean technologies, waste management, product and packaging recycling, carbon emissions, energy efficiency, and pollution prevention is a fundamental driver for SMEs' adoption of corporate environmental reporting practices [66,76]. Firms that emphasize improving their environmental performance through reducing undesirable outputs such as wastes, $\mathrm{CO} 2$ emissions, and pollutants during manufacturing processes enhance their economic performance [77].

Triguero et al. [78] stated that SMEs show promising compliance with environmental regulations, while Panwar et al. [79] argued that environmental regulations encourage 
SMEs' engagement in corporate environmental reporting practices along with the perceived cost reductions. Luo et al. [15] showed that regulations and incentives are essential for implementing green manufacturing in Chinese manufacturing SMEs. Testa et al. [80] argued that maximizing the value of resources enables firms to gain and sustain competitive advantages. In this regard, environmental regulations need to encourage the circulation of resources and limit the use of materials in the manufacturing process to maximize resources value and guide firms to explore innovative production modes.

The world has witnessed an increasing level of political and social awareness of the significance of developing environmental responsibility at the organizational level with only $20 \%$ of firms adhering to environmental regulations and showing a high degree of environmental responsibility [67]. In the Chinese context, the "Thirteenth Five-Year Plan" was declared to promote and implement sustainability [81]. Sustainable manufacturing ensures that products are fully recyclable, completely disassembled, and protect the environment [82].

Zhao et al. [83] showed that efficiency improvement and $\mathrm{CO} 2$ reduction are positively related to market-based regulations and government subsidies. Porter and Linde [53] argued that proper design and effective implementation of environmental regulation can mitigate carbon dioxide emission and stimulate more green innovation, which in turn offsets the regulatory costs and increases profitability. Xing et al. [84] found that environmental regulation can help improve financial performance via sustainability innovation and green dynamic capability. Thus, this study argues that environmental regulations strengthen the association between sustainable manufacturing and sustainable performance and formulates the following hypothesis:

Hypothesis 4 (H4). Environmental regulations have a significant moderating impact on the relationship between SMPs and sustainable performance.

\section{Materials and Methods}

This study employed a quantitative research method and used structured questionnaires for data collection. Self-administered questionnaires were distributed to owners/managers of manufacturing SMEs located in Zhejiang, Jiangsu, and Guangzhou provinces. Recognizing the wide geographic space of China mainland, the fact that owners/managers of SMEs are always busy, and the difficulty of obtaining their online contacts, researchers relied on convenience sampling and decided to use a printed questionnaire. Bryman and Bell [85] advocated the use of convenience-sampling procedures in the business and management field and argued that it can generate a representative sample more than other sampling approaches. Researchers employed three local citizens to assist in the data collection process who undertook the responsibilities of contacting and following up with respondents. Assistants received a comprehensive explanation about the purpose of the research and targeted research participants. Respondents were requested to fill in the structured questionnaire based on a five-point Likert scale ranging from "strongly disagree" to "strongly agree".

The survey questionnaire was assessed by a panel of 2 operations management professors and 8 Ph.D. students in business and management fields. They recommended minor changes to some items to improve the clarity and directness of the survey. Researchers developed the final version of the English questionnaire based on the panel's recommendation and translated it into Chinese (Mandarin). A reverse independent translation from Chinese to English was performed to undertake minor wording modification and to ensure consistency.

A total of 500 printed questionnaires were administered to owners/managers of manufacturing SMEs between April-June 2012. A cover letter was attached with the survey to ensure confidentiality. Phone calls, WeChat, and face-to-face contacts were used to follow up with respondents and maximize response rates. The data collection process yielded an 
adequate response rate of $57.6 \%$ [86]. Out of the 500 distributed questionnaires, 313 were returned, and 288 were completed and valid for further analysis.

\section{Measures}

Measurement scales of study variables were duly adapted from the extant mature literature. Six items were used to measure SMPs based on Despeisse et al.'s and Rusinko's $[12,87]$ previous studies. This study used Aboelmaged's [88] measurement scale of SMEs' competitive capabilities related to product cost, production flexibility, product quality, and product delivery. Product cost has three items that assess manager's perception of overhead costs, price of product, and cost of materials. Production flexibility was assessed using four items related to processes of altering the amount of products quickly, introducing a new product, ability of providing a variety of products, and providing customized products. Product quality was measured using five items that evaluate SME ability to provide high-quality products with required specification and minor defects. Finally, product delivery was measured using two items that evaluate SME dependable and fast delivery of products. The environmental regulation measurement scale was adapted from Lai and Wong [89] and Carter et al. [10]. Finally, SMEs' sustainable performance was assessed based on three dimensions of sustainability: economic, environmental, and social adapted from [90,91]. English version of survey questionnaire is presented in Appendix A.

\section{Results}

Table 1 summarizes the profile of manufacturing SMEs. Respondents were requested to identify the length of adopting SMPs and its inclusion in their firm strategy. Findings revealed that $72 \%$ of Chinese manufacturing SMEs were actively adopting SMPs and consider it as a strategic intention for more than 10 years. For SME size, $63 \%$ of the valid sample are considered to be small-sized SMEs followed by $24 \%$ medium-sized SMEs. Manufacturing SMEs were aged between 16-20 (39\%) and more than 20 years (34\%) and concentrated in textile and garment (30\%) and electronic, optical, electrical products (28\%).

Table 1. SMEs' profile.

\begin{tabular}{ccc}
\hline & Frequency & $\%$ \\
\hline Active adoption of SMPs & & \\
\hline Less than 5 years & 26 & 9 \\
5-10 years & 55 & 19 \\
More than 10 years & 207 & 72 \\
\hline SME Size & & \\
\hline Micro (up to 50 employees) & 37 & 13 \\
Small (51-150 employees) & 181 & 63 \\
Medium (151-600 employees) & 70 & 24 \\
\hline Industry & & \\
\hline Textile and garment & 92 & 32 \\
Chemical, rubber, and plastic products & 49 & 20 \\
Metal and machinery & 58 & 31 \\
Electronic, optical, and electrical products & 89 & 3 \\
\hline SME Age & & 9 \\
\hline 1-5 years & 9 & 15 \\
6-10 years & 26 & 39 \\
11-15 years & 43 & 34 \\
\hline 20 -20 years & 112 &
\end{tabular}




\subsection{Assessment of Measurement Model}

The data analysis process involved two stages: assessment and evaluation of the measurement model. The proposed model was assessed through PLS-SEM using SmartPls (3.2.6). The measures of assessing the proposed model involved composite reliability, convergent validity, and discriminant validity. Table 2 reports the mean score, reliability, and validity dimensions of constructs. The reported mean scores of constructs ranged between 3.79 (product delivery) and 4.22 (environmental regulation). This indicated that respondents have a high consensus on undertaking SMPs, gaining competitive advantages, adhering to environmental regulations, and maintaining a good level of sustainable performance. All items of constructs have factor loadings of more than 0.40; all constructs have a composite reliability $(\mathrm{CR})$ value greater than 0.7 and an average variance extracted (AVE) value greater than 0.5. [86]. Accordingly, the reported data are reliable and valid for further analysis.

Table 2. Constructs reliability and validity.

\begin{tabular}{|c|c|c|c|c|c|c|}
\hline Construct & Indicators & FL & Mean & CA & CR & AVE \\
\hline \multirow{6}{*}{$\begin{array}{l}\text { Sustainable Manufacturing } \\
\text { Practices (SMPs) }\end{array}$} & SMPs 1 & 0.883 & \multirow{6}{*}{4.11} & \multirow{6}{*}{0.88} & \multirow{6}{*}{0.90} & \multirow{6}{*}{0.73} \\
\hline & SMPs 2 & 0.891 & & & & \\
\hline & SMPs 3 & 0.854 & & & & \\
\hline & SMPs 4 & 0.856 & & & & \\
\hline & SMPs 5 & 0.807 & & & & \\
\hline & SMPs 6 & 0.798 & & & & \\
\hline \multirow{3}{*}{$\begin{array}{l}\text { Product Cost } \\
\text { (PC) }\end{array}$} & PC1 & 0.832 & \multirow{3}{*}{4.13} & \multirow{3}{*}{0.88} & \multirow{3}{*}{0.91} & \multirow{3}{*}{0.78} \\
\hline & PC2 & 0.851 & & & & \\
\hline & PC3 & 0.849 & & & & \\
\hline \multirow{4}{*}{$\begin{array}{l}\text { Production Flexibility } \\
\text { (PF) }\end{array}$} & PF1 & 0.861 & \multirow{4}{*}{3.92} & \multirow{4}{*}{0.79} & \multirow{4}{*}{0.81} & \multirow{4}{*}{0.66} \\
\hline & PF2 & 0.808 & & & & \\
\hline & PF3 & 0.853 & & & & \\
\hline & PF4 & 0.778 & & & & \\
\hline \multirow{5}{*}{$\begin{array}{l}\text { Product Quality } \\
\text { (PQ) }\end{array}$} & PQ1 & 0.816 & \multirow{5}{*}{3.86} & \multirow{5}{*}{0.83} & \multirow{5}{*}{0.87} & \multirow{5}{*}{0.71} \\
\hline & PQ2 & 0.739 & & & & \\
\hline & PQ3 & 0.870 & & & & \\
\hline & PQ4 & 0.812 & & & & \\
\hline & PQ5 & 0.866 & & & & \\
\hline \multirow{2}{*}{ Product Delivery (PD) } & PD1 & 0.708 & \multirow{2}{*}{3.79} & \multirow{2}{*}{0.86} & \multirow{2}{*}{0.89} & \multirow{2}{*}{0.72} \\
\hline & PD2 & 0.764 & & & & \\
\hline \multirow{4}{*}{$\begin{array}{l}\text { Environmental Regulation } \\
\text { (ER) }\end{array}$} & ER1 & 0.729 & \multirow{4}{*}{4.22} & \multirow{4}{*}{0.81} & & \\
\hline & ER2 & 0.808 & & & & \\
\hline & ER3 & 0.765 & & & 0.84 & 0.74 \\
\hline & ER4 & 0.872 & & & & \\
\hline & SP1 & 0.814 & & & & \\
\hline & SP2 & 0.713 & & & & \\
\hline & SP3 & 0.805 & & & & \\
\hline & SP4 & 0.783 & & & & \\
\hline & SP5 & 0.767 & & & & \\
\hline Sustainable Performance & SP6 & 0.858 & 4.09 & 0.80 & 0.82 & 0.69 \\
\hline & SP7 & 0.863 & & & & \\
\hline & SP8 & 0.817 & & & & \\
\hline & SP9 & 0.763 & & & & \\
\hline & SP10 & 0.815 & & & & \\
\hline & SP11 & 0.826 & & & & \\
\hline
\end{tabular}

Note: $\mathrm{FL}=$ factor loadings, $\mathrm{CA}=$ Cronbach alpha, $\mathrm{CR}=$ composite reliability, and $\mathrm{AVE}=$ average variance.

Discriminant validity was tested using Fornell and Larker's criterion to ensure that constructs are not correlated with each other [92]. Discriminant validity is achieved when the reported construct's square root (average variance extracted (AVE) is greater than its 
bivariate correlations with other constructs. The reported square roots of AVE values were higher than their respective interconstruct correlations as shown in Table 3. Accordingly, discriminant validity is established.

Table 3. Discriminant validity.

\begin{tabular}{cccccccccc}
\hline & SMPs & PC & PF & PQ & PD & ER & ES & ENS & SS \\
\hline SMPs & 0.836 & & & & & & & & \\
PC & 0.771 & 0.802 & & & & & & & \\
PF & 0.593 & 0.674 & 0.790 & & & & & & \\
PQ & 0.552 & 0.658 & 0.707 & 0.843 & & & & & \\
PD & 0.574 & 0.734 & 0.658 & 0.545 & 0.527 & & & & \\
ER & 0.647 & 0.811 & 0.800 & 0.659 & 0.604 & 0.830 & & & \\
ES & 0.623 & 0.708 & 0.625 & 0.467 & 0.610 & 0.476 & 0.861 & & \\
ENS & 0.703 & 0.699 & 0.642 & 0.691 & 0.576 & 0.368 & 0.531 & 0.787 & \\
SP & 0.661 & 0.729 & 0.579 & 0.586 & 0.516 & 0.418 & 0.511 & 0.472 & 0.811 \\
\hline
\end{tabular}

SMPs = sustainable manufacturing practices, $\mathrm{PC}=$ product cost, $\mathrm{PF}=$ production flexibility, $\mathrm{PQ}=$ product quality $\mathrm{PD}=$ product delivery, $\mathrm{ER}=$ environmental regulations, and $\mathrm{SP}=$ sustainable performance.

For the further establishment of discriminant validity, this study used heterotraitmonotrait ratio of correlations (HTMT). According to Henseler et al. [93], this criterion assumes that discriminant validity is confirmed when the indicators of two constructs with HTML values below 90 are acceptable. Discriminant validity is established as the highest reported HTMT values between SMPs, and the product cost was 0.87 as summarized in Table 4.

Table 4. Heterotrait-monotrait ratio (HTMT).

\begin{tabular}{cccccccc}
\hline & SMPs & PC & PF & PQ & PD & ER & SP \\
\hline SMPs & & & & & & & \\
PC & 0.871 & & & & & & \\
PF & 0.623 & 0.774 & & & & \\
PQ & 0.552 & 0.658 & 0.607 & & & \\
PD & 0.574 & 0.534 & 0.598 & 0.587 & & \\
ER & 0.647 & 0.411 & 0.486 & 0.522 & 0.514 & \\
SP & 0.611 & 0.608 & 0.525 & 0.467 & 0.365 & 0.493 & \\
\hline
\end{tabular}

\subsection{Evaluation of the Structural Model}

The evaluation of the measurement model was performed through testing collinearity among constructs and hypotheses testing based on the significance level of regression analysis. Before conducting regression analysis and testing hypotheses, a collinearity test was performed using the variance inflation factor (VIF) between predictor variables especially when there are mediating or moderating variables [86]. VIF values should be below 5 . Table 5 shows the collinearity assessment of predicting variables. Findings showed that there is no collinearity among predictors, as all VIF values are below 5 . Table 6 shows the bootstrapping results of direct effects and indirect path in SmarPls for mediation and moderating analysis.

The first research hypothesis tested the direct influence of SMPs on SMEs' sustainable performance. The results of the direct path showed a significant effect of SMPs on sustainable performance $(\beta=0.47, \mathrm{t}=9.95, p<0.01)$. Therefore, the first hypothesis is accepted. The second hypothesis examined the impact of SMPs on four competitive capabilities: product cost, production flexibility, product quality, and product delivery. Findings revealed a positive significant impact of SMPs on product cost $(\beta=0.41, \mathrm{t}=8.35, p<0.01)$, production flexibility $(\beta=0.39, \mathrm{t}=7.69, p<0.01)$, product quality $(\beta=0.28, \mathrm{t}=6.29, p<0.01)$, and product delivery $(\beta=0.22, \mathrm{t}=5.18, p<0.01)$. Thus, the second hypothesis is accepted. 
Table 5. Collinearity assessment (inner VIF values).

\begin{tabular}{cccc}
\hline \multicolumn{1}{c}{ Direct Effects } & \multicolumn{2}{c}{ Indirect Effects } \\
\hline Predictor & VIF & Predictor & VIF \\
\hline SMPs & 1.95 & SMPs & 1.51 \\
\hline PC & 1.69 & ER & 1.74 \\
\hline PF & 1.57 & SMPs * ER & 1.59 \\
\hline PQ & 1.63 & & \\
\hline PD & 1.37 & & \\
\hline
\end{tabular}

$\overline{\mathrm{VIF}}=$ variance inflation factor. ${ }^{*} p<0.05$.

Table 6. PLS regression results.

\begin{tabular}{ccccc}
\hline Direct Path & & & $\boldsymbol{\beta}$ & $\mathbf{t}$-Value \\
\hline Direct impact of SMPs on SP & $\mathbf{H} \mathbf{1}$ & $\mathrm{SMPs} \rightarrow \mathrm{SP}$ & 0.47 & $9.95^{* *}$ \\
\hline \multirow{3}{*}{ Direct impact of SMPs on CC } & $\mathbf{H} \mathbf{2}_{\mathbf{a}}$ & $\mathrm{SMPs} \rightarrow \mathrm{PC}$ & 0.41 & $8.35^{* *}$ \\
\cline { 2 - 5 } & $\mathbf{H} \mathbf{2}_{\mathbf{b}}$ & $\mathrm{SMPs} \rightarrow \mathrm{PF}$ & 0.39 & 7.69 \\
\cline { 2 - 5 } & $\mathbf{H} \mathbf{2}_{\mathbf{c}}$ & $\mathrm{SMPs} \rightarrow \mathrm{PQ}$ & 0.28 & 6.29 \\
\cline { 2 - 5 } & $\mathbf{H} \mathbf{2}_{\mathbf{d}}$ & $\mathrm{SMPs} \rightarrow \mathrm{PD}$ & 0.22 & $5.18^{* *}$ \\
\hline Indirect Path & & & $\beta$ & $\mathrm{t}$-value \\
\hline \multirow{2}{*}{ Mediating effect of CC } & $\mathbf{H 3} \mathbf{3}_{\mathbf{a}}$ & $\mathrm{SMPs} \rightarrow \mathrm{PC} \rightarrow \mathrm{SP}$ & 0.26 & $6.17^{* *}$ \\
\cline { 2 - 5 } & $\mathbf{H} \mathbf{3}_{\mathbf{b}}$ & $\mathrm{SMPs} \rightarrow \mathrm{PF} \rightarrow \mathrm{SP}$ & 0.18 & $4.87^{* *}$ \\
\cline { 2 - 5 } & $\mathbf{H} \mathbf{3}_{\mathbf{c}}$ & $\mathrm{SMPs} \rightarrow \mathrm{PQ} \rightarrow \mathrm{SP}$ & 0.11 & 2.43 \\
\cline { 2 - 5 } & $\mathbf{H} \mathbf{3}_{\mathbf{c}}$ & $\mathrm{SMPs} \rightarrow \mathrm{PD} \rightarrow \mathrm{SP}$ & 0.14 & 2.85 \\
\hline Moderating effect of ER & $\mathbf{H 4}$ & $\mathrm{SMPs} * \mathrm{ER} \rightarrow \mathrm{SP}$ & 0.29 & 7.16 \\
\hline
\end{tabular}

SMPs = sustainable manufacturing practices, $\mathrm{PC}=$ product cost, $\mathrm{PF}=$ production flexibility, $\mathrm{PQ}=$ product quality, $\mathrm{PD}=$ product delivery, $\mathrm{ER}=$ environmental regulations, and $\mathrm{SP}=$ sustainable performance. ${ }^{*} p<0.05 ;{ }^{* *} p<0.01$

The third hypothesis tested the mediating impact of the four competitive capabilities on the relationship between SMPs and sustainable performance of SMEs. Muller et al. [94] identified four conditions for a given variable to functions as a mediator: (1) the independent variable (SMPs) has a significant impact on the dependent variable (sustainable performance) without the presence of a mediator (competitive capabilities); (2) the independent variable has a significant effect on the mediating variable; (3) the mediator variable has a significant impact on the dependent variable; and (4) the indirect effect through the mediating variable (SMPs $\rightarrow$ competitive capabilities $\rightarrow$ sustainable performance) must be significant after including a mediator. The mediation analysis of competitive capabilities on the relationship between sustainable manufacturing and sustainable performance showed a significant indirect impact of product $\operatorname{cost}(\beta=0.26, \mathrm{t}=6.17, p<0.01)$, production flexibility $(\beta=0.18, \mathrm{t}=4.87, p<0.01)$, product quality $(\beta=0.11, \mathrm{t}=2.43, p<0.05)$, and product delivery $(\beta=0.14, t=2.85, p<0.05)$. The presence of the mediators has resulted in a reasonable reduction in the value of the path coefficient from 0.47 to 0.26 (product cost), from 0.47 to 0.18 (production flexibility), from 0.47 to 0.11 (product quality), and from 0.47 to 0.14 (product delivery). However, the significant relationship between the SMPs and SMEs' sustainable performance remained significant with the presence of mediators (PC, $\mathrm{PF}, \mathrm{PQ}$, and PD) (t-values 6.17, 4.87, 2.43, 2.85). Therefore, hypothesis 3 is accepted, and it can be inferred that the positive relationship between SMPs and sustainable performance was positively mediated by competitive capabilities. 
The fourth hypothesis examined the moderating impact of environmental regulations on the relationship between SMP and sustainable performance of SMEs. The moderating impact was estimated using a standardized product-indicator approach in the PLS path model [95]. Findings showed that the impact of SMP on SMEs' sustainable performance is strengthened by the presence of environmental regulations $(\beta=0.29, \mathrm{t}=2.43, p<0.01)$. Despite the inclusion of environmental regulations as a moderator causing a remarkable reduction of the path coefficient value from 0.47 to 0.29 , the relationship between SMPs and sustainable performance remained significant. This leads to accepting hypothesis 4 and concluding that the relationship between SMPs and sustainable performance is strengthened by environmental regulations. Table 7 summarizes the results of hypotheses testing.

Table 7. Summary of hypotheses testing results.

\begin{tabular}{ccc}
\hline Hypothesis & Path Relationship & Result \\
\hline $\mathbf{H} \mathbf{1}$ & $\mathrm{SMPs} \rightarrow \mathrm{SP}$ & Approved \\
\hline $\mathbf{H} \mathbf{2}_{\mathbf{a}}$ & $\mathrm{SMPs} \rightarrow \mathrm{PC}$ & Approved \\
\hline $\mathbf{H} \mathbf{2}_{\mathbf{b}}$ & $\mathrm{SMPs} \rightarrow \mathrm{PF}$ & Approved \\
\hline $\mathbf{H} \mathbf{2}_{\mathbf{c}}$ & $\mathrm{SMPs} \rightarrow \mathrm{PQ}$ & Approved \\
\hline $\mathbf{H} \mathbf{2}_{\mathbf{d}}$ & $\mathrm{SMPs} \rightarrow \mathrm{PD}$ & Approved \\
\hline $\mathbf{H} \mathbf{3}_{\mathbf{a}}$ & $\mathrm{SMPs} \rightarrow \mathrm{PC} \rightarrow \mathrm{SP}$ & Approved \\
\hline $\mathbf{H} \mathbf{3}_{\mathbf{b}}$ & $\mathrm{SMPs} \rightarrow \mathrm{PF} \rightarrow \mathrm{SP}$ & Approved \\
\hline $\mathbf{H} \mathbf{3}_{\mathbf{c}}$ & $\mathrm{SMPs} \rightarrow \mathrm{PQ} \rightarrow \mathrm{SP}$ & Approved \\
\hline $\mathbf{H} \mathbf{3}_{\mathbf{c}}$ & $\mathrm{SMPs} \rightarrow \mathrm{PD} \rightarrow \mathrm{SP}$ & Approved \\
\hline $\mathbf{H} \mathbf{4}$ & $\mathrm{SMPs}{ }^{*} \mathrm{ER} \rightarrow \mathrm{SP}$ & Approved \\
\hline
\end{tabular}

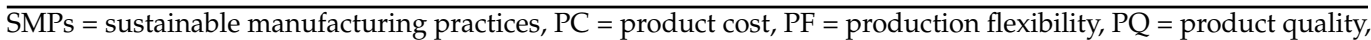
$\mathrm{PD}=$ product delivery, $\mathrm{ER}=$ environmental regulations, and $\mathrm{SP}=$ sustainable performance.

\section{Discussion}

Drawing on NRBV theory, this study proposed and tested a model that extends the scholarship on SMPs and SMEs' sustainable performance. In this regard, the current study examined the mediating role of competitive capabilities and moderating influence of environmental regulation on the relationship between SMPs and SMEs' sustainable performance. Findings revealed that SMEs' sustainable performance is positively related to adopting SMPs. Hami et al. [96] underlined that firms' economic sustainable performance is positively related to internal sustainability practices, while environmental and social sustainable responsibility has a negative impact on economic results. Luo et al. [15] indicated that the accelerated development of Chinese manufacturing SMEs has resulted in a significant contribution to economic growth while causing resource-abuse problems and environmental pollution. In contrast to large corporations, SMEs maintain limited financial stability, ineffective resources management, and lack of awareness of the benefits of adopting sustainable practices which discourage them to devote sufficient investment in such activities [97]. Yang et al. [98] indicated that maintaining energy efficiency leads to enhancing organizational financial performance.

In addition, SMPs allow SMEs to maintain competitive capabilities pertaining to product cost, production flexibility, product quality, and delivery. Manufacturers should maintain the efficient use of resources and energy utilization to reduce and $\mathrm{CO} 2$ emissions and to reduce manufacturing costs [97]. Nakano [99] reported that adopting sustainable manufacturing enables firms to increase the total value that benefits natural resources and the ecosystem. Mittal and Sangwan [75] indicated that sustainable manufacturing has a positive significant influence on providing sustainable and valuable products through the efficient use of resources such as raw materials, labor, and energy.

Further, competitive capabilities have a significant mediating impact on the relationship between SMPs and SMEs' sustainable performance. This research indicated that gain- 
ing competitive capabilities would motivate SMEs to adopt SMPs and positively influence their sustainable performance. The research findings are compatible with Schoenherr [52], who indicated that SMPs are closely related to achieving competitive advantages regarding production flexibility, product cost, quality, and delivery. In conjunction with the NRBV [25], firms can gain competitive advantages through undertaking environmental initiatives in different stages: designing, manufacturing, packaging, quality control, delivery, and sourcing. Climate change and environmental pressures have forced SMEs to rethink the sources of competitive advantages [17]. Triguero et al. [78] underlined that SMEs' adoption of environmental practices varies across industry contexts. Despite the competitive advantages gained from adopting environmental practices, there is variance in the actual involvement of SMEs in sustainability [19]. This study argues that SMEs undertaking SMPs would maintain a favorable sustainable performance when they develop competitive capabilities related to the cost, quality, and delivery of a product and production flexibility.

Moreover, the results of the study revealed that environmental regulations played a significant influence on the linkage between SMPs and SMEs' sustainable performance. This finding inferred the effective enforcement of environmental regulations in China and SMEs' compliance with it. The presence and enforcement of environmental regulations strengthen the positive relationship between SMPs and sustainable performance. Zhang et al. [16] reported that the sustainability priorities of Chinese companies during COVID-19 and into the postpandemic phase emphasized the social dimension, whereas the postpandemic phase witnessed a great emphasis on economic sustainability while little attention was paid to environmental sustainability. Adopting sustainability is a major challenge for SMEs as they prioritize economic performance over social and environmental concerns. However, SMEs try to implement corporate sustainability to adhere to relevant regulations and policies [100]. Prior research indicates that small businesses perceive lower benefits of involvement in sustainable development; thus, they may not comply with the minimum environmental regulation [101], while large enterprises maintain sufficient resources and capabilities to engage in environmental protection proactively and respond to customers' demands or competitors' initiatives [102]. Shankar [74] argued that SMPs are positively associated with environmental laws and rules. Hamann et al. [103] revealed an insignificant impact of environmental regulations on engagement in pro-environmental behaviors among South African wine-producing SMEs. As a fundamental environmental initiative, Abdul-Rashid et al. [38] argued that SMPs contribute significantly to preserving the environment and improving the quality of life when undertaking manufacturing activities. In their research on building a sustainable business in Chinese SMEs, Yu and Bell [104] reveal an apparent contradiction towards sustainability and found that the level of firms ${ }^{\prime}$ engagement was motivated by corporate image, followed by governmental legislation.

\section{Conclusions}

This paper examined the direct influence of SMPs on Chinese manufacturing SMEs sustainable performance with an emphasis on the mediating role of competitive advantages and moderating effect of environmental regulations. The findings of this research indicated that SMPs are essential for SMEs to enhance sustainable performance [33,34], but the previously underexplored mediating effect of competitive capabilities generally indicates that gaining competitive capabilities pertaining to product cost, quality, and delivery and production flexibility plays an escalating influence. Further, the interaction between SMPs and adherence to environmental regulations was found to positively influence SMEs' sustainable performance. This research advocates the need to examine the outcomes of SMPs as a fundamental research stream of sustainability.

This paper contributes to the extant literature on sustainable manufacturing and sustainable performance by extending our knowledge about the competitive capabilities gained from the application of SMPs and enhancing sustainable performance in SMEs. Further, the association between SMPs and SMEs' sustainable performance was 
strengthened by the presence and enforcement of environmental regulations. This research presents some insights into the relationship between SMPs and SMEs' sustainable performance. The results of this research can serve as a guideline for manufacturers to adopt a sustainability-based manufacturing system that integrates sustainability into their processes and strategies to gain competitive capabilities and contribute significantly to the environment and stakeholders. Further, the research findings can equip policymakers with a solid foundation to develop and implement environmental regulations that encourage owners and managers of manufacturing SMEs in China to adopt SMPs and encourage their contribution to sustainability. Further, the development of environmental regulations should consider the nature of manufacturing SMEs, ensure they maintain competitive advantages, and enhance their sustainable performance.

This research has some limitations that may influence its generalizability. First, environmental regulations in China are divided into command-controlled, market-oriented, and voluntary [105]. The current study did not differentiate among such types of environmental regulations and addressed environmental regulation as a general concept. Second, the study was undertaken in a Chinese context that maintains its unique cultural and regulative system. Thus, the findings of this research may not be applicable in different contexts. Finally, the small sample size may bring challenges for generalizing the research findings.

Future research may focus on identifying the fundamental SMPs adopted by SMEs and investigate how such SMPs allow SMEs to gain competitive capabilities pertaining to product cost, production flexibility, product quality, and delivery. Future empirical research may examine the indirect impact of different types of environmental regulations on firms sustainable performance in different contexts.

Author Contributions: Conceptualization, H.A. and T.C.; data curation, T.C. and Y.H.; formal analysis, H.A.; methodology, H.A. and T.C.; project administration, H.A. and Y.H.; resources, Y.H.; supervision, H.A. and Y.H.; writing-original draft, H.A. and T.C.; writing-review and editing, H.A. All authors have read and agreed to the published version of the manuscript.

Funding: This research was supported by the postdoctoral research fund provided to first author, Zhejiang Gongshang University, School of Business Administration.

Institutional Review Board Statement: The study was conducted according to the guidelines of the Declaration of Helsinki, and approved by the school of business administration, Zhejiang Gongshang University.

Informed Consent Statement: Consent was obtained from all subjects involved in the study.

Data Availability Statement: The data presented in this study are available on request from the first author. The data are not publicly available due to [permission requested from the Project supervisor: Hao].

Conflicts of Interest: The authors declare no conflict of interest.

\section{Appendix A}

Table A1. Survey questionnaire.

\begin{tabular}{ccc}
\hline Construct & & Items \\
\hline & SMPs 1 & We use energy efficiently \\
Sustainable & SMPs 2 & We improve water usage \\
Manufacturing & SMPs 3 & We use materials efficiently \\
Practices & SMPs 4 & We reduce CO emissions $^{\text {a }}$ \\
& SMPs 5 & We reduce waste water \\
& SMPs 6 & We reduce generating solid waste \\
\hline
\end{tabular}


Table A1. Cont.

\begin{tabular}{|c|c|c|}
\hline Construct & & Items \\
\hline $\begin{array}{l}\text { Competitive } \\
\text { Capabilities }\end{array}$ & $\begin{array}{l}\text { PC1 } \\
\text { PC2 } \\
\text { PC3 } \\
\text { PF1 } \\
\text { PF2 } \\
\text { PF3 } \\
\text { PF4 } \\
\text { PQ1 } \\
\text { PQ2 } \\
\text { PQ3 } \\
\text { PQ4 } \\
\text { PQ5 } \\
\text { PD1 } \\
\text { PD2 }\end{array}$ & $\begin{array}{c}\text { We maintain lower overhead costs } \\
\text { We provide lower price for products/services } \\
\text { We maintain lower cost of materials } \\
\text { We can alter the amount of products/services quickly } \\
\text { We introduce new products/services quickly } \\
\text { We provide a wide variety of products/services } \\
\text { We offer customized products/services to meet customer needs } \\
\text { We provide highly qualified products/services } \\
\text { Our products/services have low defects } \\
\text { Specifications of products/services are appropriate } \\
\text { We maintain appropriate working conditions and safety } \\
\text { Our goods/services have no harmful impact on the environment } \\
\text { We provide a dependable delivery of products/services } \\
\text { We provide fast delivery of products/services }\end{array}$ \\
\hline $\begin{array}{l}\text { Environmental } \\
\text { Regulation (ER) }\end{array}$ & $\begin{array}{l}\text { ER1 } \\
\text { ER2 } \\
\text { ER3 } \\
\text { ER4 }\end{array}$ & $\begin{array}{l}\text { Enforcement of ER improves SMPs in our company } \\
\text { ER is the fundamental reason why we practice SMPs } \\
\text { ER improves our company's growth } \\
\text { Our company's environmental efforts can improve current ER }\end{array}$ \\
\hline Sustainable Performance (SP) * & $\begin{array}{l}\text { ES1 } \\
\text { ES2 } \\
\text { ES3 } \\
\text { ENS1 } \\
\text { ENS2 } \\
\text { ENS3 } \\
\text { ENS4 } \\
\text { SS1 } \\
\text { SS2 } \\
\text { SS3 } \\
\text { SS4 }\end{array}$ & $\begin{array}{c}\text { We maintain lower operating cost } \\
\text { We achieve growth in market value } \\
\text { We maintain a growing profitability } \\
\text { We reduce environmental business wastages } \\
\text { We generate lower emissions / units per production } \\
\text { We use limited material/output } \\
\text { We use limited fuel and energy } \\
\text { We ensure employees' safety and health } \\
\text { We maintain good relationship with employees } \\
\text { We provide regular training and education to employees } \\
\text { We receive fewer consumer complaints }\end{array}$ \\
\hline
\end{tabular}

* SP = ES = economic sustainability, ENS = environmental sustainability, and SS = social sustainability.

\section{References}

1. Hashmi, R.; Alam, K. Dynamic relationship among environmental regulation, innovation, $\mathrm{CO}_{2}$ emissions, population, and economic growth in OECD countries: A panel investigation. J. Clean. Prod. 2019, 231, 1100-1109. [CrossRef]

2. Ashford, N.A.; Hall, R.P. Achieving Global Climate and Environmental Goals by Governmental Regulatory Targeting. Ecol. Econ. 2018, 152, 246-259. [CrossRef]

3. Gupta, S.; Kumar, V. Sustainability as corporate culture of a brand for superior performance. J. World Bus. 2013, 48, 311-320. [CrossRef]

4. Aboelmaged, M. The drivers of sustainable manufacturing practices in Egyptian SMEs and their impact on competitive capabilities: A PLS-SEM model. J. Clean. Prod. 2018, 175, 207-221. [CrossRef]

5. Agan, Y.; Acar, M.F.; Borodin, A. Drivers of environmental processes and their impact on performance: A study of Turkish SMEs. J. Clean. Prod. 2013, 51, 23-33. [CrossRef]

6. Chen, D.; Thiede, S.; Schudeleit, T.; Herrmann, C. A holistic and rapid sustainability assessment tool for manufacturing SMEs. CIRP Ann.-Manuf. Technol. 2014, 63, 437-440. [CrossRef]

7. International Trade Administration. How Does Commerce Define Sustainable Manufacturing? U.S. Department of Commerce. 2011. Available online: https://blog.trade.gov/tag/sustainable-manufacturing-initiative/ (accessed on 11 May 2021).

8. Garetti, M.; Mummolo, G.; Taisch, M. Editorial: Special issue on sustainable manufacturing. Prod. Plan. Control 2012, 23, 79-82. [CrossRef]

9. Jakob, M.; Marschinski, R.; Hübler, M. Between a Rock and a Hard Place: A Trade-Theory Analysis of Leakage Under Productionand Consumption-Based Policies. Environ. Resour. Econ. 2013, 56, 47-72. [CrossRef]

10. Carter, C.R.; Rogers, D.S. A framework of sustainable supply chain management: Moving toward new theory. Int. J. Phys. Distrib. Logist. Manag. 2008, 38, 360-387. [CrossRef]

11. Seliger, G. Sustainability in Manufacturing: Recovery of Resources in Product and Material Cycles; Springer: Berlin, Germany, 2007.

12. Despeisse, M.; Mbaye, F.; Ball, P.D.; Levers, A. The emergence of sustainable manufacturing practices. Prod. Plan. Control 2012, 23, 354-376. [CrossRef] 
13. Zambrano-Monserrate, M.A.; Ruano, M.A.; Sanchez-Alcalde, L. Indirect effects of COVID-19 on the environment. Sci. Total Environ. 2020, 728, 138813. [CrossRef] [PubMed]

14. Huang, W.; Morawska, L. Face masks could raise pollution risks. Nature 2019, 574, 29-30. [CrossRef] [PubMed]

15. Luo, Y.; Jie, X.; Li, X.; Yao, L. Ranking Chinese SMEs green manufacturing drivers using a novel hybrid multi-criterion decisionmaking model. Sustainability 2018, 10, 2661. [CrossRef]

16. Zhang, D.; Hao, M.; Morse, S. Is environmental sustainability taking a backseat in china after covid-19? The perspective of business managers. Sustainability 2020, 12, 10369. [CrossRef]

17. Li, L.; Msaad, H.; Sun, H.; Tan, M.X.; Lu, Y.; Lau, A.K.W. Green innovation and business sustainability: New evidence from energy intensive industry in China. Int. J. Environ. Res. Public Health 2020, 17, 7826. [CrossRef]

18. Behjati, S. Critical Remarks About Environmentalism Implication By Iranian Smes. Eur. J. Sustain. Dev. 2017, 6, 209-219. [CrossRef]

19. Thanki, S.; Govindan, K.; Thakkar, J. An investigation on lean-green implementation practices in Indian SMEs using analytical hierarchy process (AHP) approach. J. Clean. Prod. 2016, 135, 284-298. [CrossRef]

20. Khan, Z.; Sisi, Z.; Siqun, Y. Environmental regulations an option: Asymmetry effect of environmental regulations on carbon emissions using non-linear ARDL. Energy Sources Part A: Recovery Util. Environ. Eff. 2019, 41, 137-155. [CrossRef]

21. Zailani, S.; Iranmanesh, M.; Hyun, S.S.; Ali, M.H. Applying the theory of consumption values to explain drivers'willingness to pay for biofuels. Sustainability 2019, 11, 668. [CrossRef]

22. Iranmanesh, M.; Zailani, S.; Hyun, S.S.; Ali, M.H.; Kim, K. Impact of lean manufacturing practices on firms' sustainable performance: Lean culture as a moderator. Sustainability 2019, 11, 1112. [CrossRef]

23. Mallak, S.K.; Ishak, M.B.; Mohamed, A.F.; Iranmanesh, M. Toward sustainable solid waste minimization by manufacturing firms in Malaysia: Strengths and weaknesses. Environ. Monit. Assess. 2018, 190, 1-6. [CrossRef]

24. Wu, K.J.; Chen, Q.; Qi, Y.; Jiang, X.; Gao, S.; Tseng, M.L. Sustainable development performance for small and medium enterprises using a fuzzy synthetic method-DEMATEL. Sustainability 2019, 11, 4119. [CrossRef]

25. Hart, S.L. A Natural Resource View of the Firm. Acad. Manag. Rev. 1995, 20, 986-1014. [CrossRef]

26. Aragón-Correa, J.A.; Hurtado-Torres, N.; Sharma, S.; García-Morales, V.J. Environmental strategy and performance in small firms: A resource-based perspective. J. Environ. Manag. 2008, 86, 88-103. [CrossRef] [PubMed]

27. Woo, C.; Chung, Y.; Chun, D.; Seo, H. Exploring the impact of complementary assets on the environmental performance in manufacturing SMEs. Sustainability 2014, 6, 7412-7432. [CrossRef]

28. Johnson, M.P.; Schaltegger, S. Two Decades of Sustainability Management Tools for SMEs: How Far Have We Come? J. Small Bus. Manag. 2016, 54, 481-505. [CrossRef]

29. López-Pérez, M.E.; Melero-Polo, I.; Vázquez-Carrasco, R.; Cambra-Fierro, J. Sustainability and business outcomes in the context of SMEs: Comparing family firms vs. non-family firms. Sustainability 2018, 10, 4080. [CrossRef]

30. Dey, P.K.; Yang, G.L.; Malesios, C.; De, D.; Evangelinos, K. Performance Management of Supply Chain Sustainability in Small and Medium-Sized Enterprises Using a Combined Structural Equation Modelling and Data Envelopment Analysis. Comput. Econ. 2019, 1-41. [CrossRef]

31. Prieto-Sandoval, V.; Jaca, C.; Ormazabal, M. Towards a consensus on the circular economy. J. Clean. Prod. 2018, 179, 605-615. [CrossRef]

32. Rita, D.I.G.; Ferreira, F.A.F.; Meidutè-Kavaliauskienė, I.; Govindan, K.; Ferreira, J.J.M. Proposal of a green index for small and medium-sized enterprises: A multiple criteria group decision-making approach. J. Clean. Prod. 2018, 196, 985-996. [CrossRef]

33. Afum, E.; Agyabeng-Mensah, Y.; Sun, Z.; Frimpong, B.; Kusi, L.Y.; Acquah, I.S.K. Exploring the link between green manufacturing, operational competitiveness, firm reputation and sustainable performance dimensions: A mediated approach. J. Manuf. Technol. Manag. 2020, 31, 1417-1438. [CrossRef]

34. Hong, J.; Zhang, Y.; Ding, M. Sustainable supply chain management practices, supply chain dynamic capabilities, and enterprise performance. J. Clean. Prod. 2018, 172, 3508-3519. [CrossRef]

35. Klassen, R.D.; McLaughlin, C.P. The impact of environmental management on firm performance. Manag. Sci. 1996, $42,1199-1214$. [CrossRef]

36. Zailani, S.; Jeyaraman, K.; Vengadasan, G.; Premkumar, R. Sustainable supply chain management (SSCM) in Malaysia: A survey. Int. J. Prod. Econ. 2012, 140, 330-340. [CrossRef]

37. Saqib, Z.A.; Zhang, Q. Impact of sustainable practices on sustainable performance: The moderating role of supply chain visibility. J. Manuf. Technol. Manag. 2021. Ahead-of-Print. [CrossRef]

38. Abdul-Rashid, S.H.; Sakundarini, N.; Raja Ghazilla, R.A.; Thurasamy, R. The impact of sustainable manufacturing practices on sustainability performance: Empirical evidence from Malaysia. Int. J. Oper. Prod. Manag. 2017, 37, 182-204. [CrossRef]

39. Habidin, N.F.; Eyun, M.A.; Zubir, A.F.M.; Fuzi, N.M.; Ong, S.Y.Y. The Relationship between Sustainable Manufacturing Practice and Environmental Performance in Malaysian Automotive SMEs. Int. J. Acad. Res. Bus. Soc. Sci. 2016, 6, 338-352. [CrossRef]

40. Vachon, S.; Klassen, R.D. Extending green practices across the supply chain: The impact of upstream and downstream integration. Int. J. Oper. Prod. Manag. 2006, 26, 795-821. [CrossRef]

41. Chung, Y.; Tsai, C. The Effect of Green Design Activities on New Product Strategies and Performance: An Empirical Study among High-Tech Companies. Int. J. Manag. 2007, 24, 276-288. 
42. Sroufe, R. Effects of environmental management systems on environmental management practices and operations. Prod. Oper. Manag. 2003, 12, 416-431. [CrossRef]

43. Russo, M.V.; Fouts, P.A. A resource-based perspective on corporate environmental performance and profitability. Acad. Manag. J. 1997, 40, 534-559.

44. Montabon, F.; Sroufe, R.; Narasimhan, R. An examination of corporate reporting, environmental management practices and firm performance. J. Oper. Manag. 2007, 25, 998-1014. [CrossRef]

45. Klassen, R.D.; Whybark, D.C. The impact of environmental technologies on manufacturing performance. Acad. Manag. J. 1999, 42, 599-615.

46. Çankaya, S.Y.; Sezen, B. Effects of green supply chain management practices on sustainability performance. J. Manuf. Technol. Manag. 2019, 30, 98-121. [CrossRef]

47. Vanalle, R.M.; Ganga, G.M.D.; Godinho Filho, M.; Lucato, W.C. Green supply chain managementAn investigation of pressures, practices, and performance within the Brazilian automotive supply chain. J. Clean. Prod. 2017, 151, 250-259. [CrossRef]

48. Chin, T.A.; Tat, H.H.; Sulaiman, Z. Green supply chain management, environmental collaboration and sustainability performance. Procedia CIRP 2015, 26, 695-699. [CrossRef]

49. Bhanot, N.; Rao, P.V.; Deshmukh, S.G. An integrated approach for analysing the enablers and barriers of sustainable manufacturing. J. Clean. Prod. 2017, 142, 4412-4439. [CrossRef]

50. Martins, V.W.B.; Anholon, R.; Quelhas, O.L.G.; Filho, W.L. Sustainable practices in logistics systems: An overview of companies in Brazil. Sustainability 2019, 11, 4140. [CrossRef]

51. Suh, C.J.; Lee, I.T. An empirical study on the manufacturing firm's strategic choice for sustainability in SMEs. Sustainability 2018, 10, 572. [CrossRef]

52. Schoenherr, T. The role of environmental management in sustainable business development: A multi-country investigation. Int. J. Prod. Econ. 2012, 140, 116-128. [CrossRef]

53. Porter, M.E.; Van der Linde, C. Toward a New Conception of the Environment-Competitiveness Relationship. J. Econ. Perspect. 1995, 9, 97-118. [CrossRef]

54. Bhardwaj, B.R. Role of green policy on sustainable supply chain management: A model for implementing corporate social responsibility (CSR). Benchmarking 2016, 23, 456-468. [CrossRef]

55. Paul, I.D.; Bhole, G.P.; Chaudhari, J.R. A Review on Green Manufacturing: It's Important, Methodology and its Application. Procedia Mater. Sci. 2014, 6, 1644-1649. [CrossRef]

56. Deif, A.M. A system model for green manufacturing. J. Clean. Prod. 2011, 19, 1553-1559. [CrossRef]

57. Ramayah, T.; Leen, J.; Marimuthu, M.; Omar, A.; Mohamad, O. Green Manufacturing Practices and Performance among SMEs: Evidence from a Developing Nation; IGI-Global: Hershey, PA, USA, 2013.

58. Sezen, B.; Çankaya, S.Y. Effects of Green Manufacturing and Eco-innovation on Sustainability Performance. Procedia-Soc. Behav. Sci. 2013, 99, 154-163. [CrossRef]

59. Anwar, M. Business model innovation and SMEs performance-Does competitive advantage mediate? Int. J. Innov. Manag. 2018, 22, 1850057. [CrossRef]

60. Wu, Z.; Pagell, M. Balancing priorities: Decision-making in sustainable supply chain management. J. Oper. Manag. 2011, 29, 577-590. [CrossRef]

61. Albertini, E. Does environmental management improve financial performance? A meta-analytical review. Organ. Environ. 2013, 26, 431-457. [CrossRef]

62. Jansson, J.; Nilsson, J.; Modig, F.; Hed Vall, G. Commitment to Sustainability in Small and Medium-Sized Enterprises: The Influence of Strategic Orientations and Management Values. Bus. Strategy Environ. 2017, 26, 69-83. [CrossRef]

63. Jamali, D.; Zanhour, M.; Keshishian, T. Peculiar strengths and relational attributes of SMEs in the context of CSR. J. Bus. Ethics 2009, 87, 355-377. [CrossRef]

64. Murillo, D.; Lozano, J.M. SMEs and CSR: An approach to CSR in their own words. J. Bus. Ethics 2006, 67, 227-240. [CrossRef]

65. Horak, S.; Arya, B.; Ismail, K.M. Organizational Sustainability Determinants in Different Cultural Settings: A Conceptual Framework. Bus. Strategy Environ. 2018, 27, 528-546. [CrossRef]

66. Gadenne, D.L.; Kennedy, J.; McKeiver, C. An empirical study of environmental awareness and practices in SMEs. J. Bus. Ethics 2009, 84, 45-63. [CrossRef]

67. Sáez-Martínez, F.J.; Díaz-García, C.; González-Moreno, Á. Factors promoting environmental responsibility in European SMEs: The effect on performance. Sustainability 2016, 8, 898. [CrossRef]

68. Tsvetkova, D.; Bengtsson, E.; Durst, S. Maintaining sustainable practices in SMEs: Insights from Sweden. Sustainability 2020, 12, 10242. [CrossRef]

69. Kozlowski, A.; Bardecki, M.; Searcy, C. Environmental Impacts in the Fashion Industry. J. Corp. Citizsh. 2014, 2012, 16-36. [CrossRef]

70. Eslami, Y.; Dassisti, M.; Lezoche, M.; Panetto, H. A survey on sustainability in manufacturing organisations: Dimensions and future insights. Int. J. Prod. Res. 2019, 57, 5194-5214. [CrossRef]

71. Jawahir, I.S.; Badurdeen, F.; Rouch, K.E. Innovation in Sustainable Manufacturing Education. In Proceedings of the 11th Global Conference on Sustainable Manufacturing, Berlin, Germany, 23-25 September 2013; pp. 9-16. 
72. Lechner, C.; Gudmundsson, S.V. Entrepreneurial orientation, firm strategy and small firm performance. Int. Small Bus. J. 2014, 32, 36-60. [CrossRef]

73. Saeidi, S.P.; Sofian, S.; Saeidi, P.; Saeidi, S.P.; Saaeidi, S.A. How does corporate social responsibility contribute to firm financial performance? The mediating role of competitive advantage, reputation, and customer satisfaction. J. Bus Res. 2015, 68, 341-350. [CrossRef]

74. Shankar, K.M.; Kumar, P.U.; Kannan, D. Analyzing the drivers of advanced sustainable manufacturing system using AHP approach. Sustainability 2016, 8, 824. [CrossRef]

75. Mittal, V.K.; Sangwan, K.S. Development of a model of barriers to environmentally conscious manufacturing implementation. Int. J. Prod. Res. 2014, 52, 584-594. [CrossRef]

76. Leonidou, L.C.; Christodoulides, P.; Thwaites, D. External Determinants and Financial Outcomes of an Eco-friendly Orientation in Smaller Manufacturing Firms. J. Small Bus. Manag. 2016, 54, 5-25. [CrossRef]

77. Wagner, M. How to reconcile environmental and economic performance to improve corporate sustainability: Corporate environmental strategies in the European paper industry. J. Environ. Manag. 2005, 76, 105-118. [CrossRef] [PubMed]

78. Triguero, A.; Moreno-Mondéjar, L.; Davia, M.A. Drivers of different types of eco-innovation in European SMEs. Ecol. Econ. 2013, 92, 25-33. [CrossRef]

79. Panwar, R.; Nybakk, E.; Hansen, E.; Pinkse, J. The effect of small firms' competitive strategies on their community and environmental engagement. J. Clean. Prod. 2016, 129, 578-585. [CrossRef]

80. Testa, F.; Iraldo, F.; Frey, M. The effect of environmental regulation on firms' competitive performance: The case of the building \& construction sector in some EU regions. J. Environ. Manag. 2011, 92, 2136-2144.

81. Cui, L.; Wu, K.J.; Tseng, M.L. Exploring a novel agricultural subsidy model with sustainable development: A Chinese agribusiness in Liaoning Province. Sustainability 2017, 9, 19. [CrossRef]

82. Rachuri, S.; Sriram, R.D.; Sarkar, P. Metrics, standards and industry best practices for sustainable manufacturing systems. In Proceedings of the 2009 IEEE International Conference on Automation Science and Engineering, Bangalore, India, 22-25 August 2009; pp. 472-477.

83. Zhao, X.; Yin, H.; Zhao, Y. Impact of environmental regulations on the efficiency and $\mathrm{CO}_{2}$ emissions of power plants in China. Appl. Energy 2015, 149, 238-247. [CrossRef]

84. Xing, X.; Liu, T.; Shen, L.; Wang, J. Linking environmental regulation and financial performance: The mediating role of green dynamic capability and sustainable innovation. Sustainability 2020, 12, 1007. [CrossRef]

85. Bryman, A.; Bell, E. Business Research Methods, 2nd ed.; Oxford University Press: Oxford, UK, 2007.

86. Hair, J.F., Jr.; Hult, G.T.M.; Ringle, C.; Sarstedt, M. A Primer on Partial Least Squares Structural Equation Modeling (PLS-SEM); Sage Publications: London, UK, 2016.

87. Rusinko, C. Green Manufacturing: An Evaluation of Environmentally Sustainable Manufacturing Practices and Their Impact on Competitive Outcomes. IEEE Trans. Eng. Manag. 2007, 54, 445-454. [CrossRef]

88. Aboelmaged, M.G. Linking operations performance to knowledge management capability: The mediating role of innovation performance. Prod. Plan. Control 2014, 25, 44-58. [CrossRef]

89. Lai, K.H.; Wong, C.W.Y. Green logistics management and performance: Some empirical evidence from Chinese manufacturing exporters. Omega 2012, 40, 267-282. [CrossRef]

90. Wang, Y.; Berens, G. The Impact of Four Types of Corporate Social Performance on Reputation and Financial Performance. J. Bus. Ethics 2015, 131, 337-359. [CrossRef]

91. Zhu, Q.; Sarkis, J.; Cordeiro, J.J.; Lai, K.H. Firm-level correlates of emergent green supply chain management practices in the Chinese context. Omega 2008, 36, 577-591. [CrossRef]

92. Ringle, C.M.; Sarstedt, M.; Mooi, E.A. Response-Based Segmentation Using Finite Mixture Partial Least Squares: Theoretical Foundations and an Application to American Customer Satisfaction Index Data. Ann. Inf. Syst. 2010, 8, 19-49.

93. Henseler, J.; Ringle, C.M.; Sarstedt, M. A new criterion for assessing discriminant validity in variance-based structural equation modeling. J. Acad. Mark. Sci. 2015, 43, 115-135. [CrossRef]

94. Muller, D.; Judd, C.M.; Yzerbyt, V.Y. When moderation is mediated and mediation is moderated. J. Pers. Soc. Psychol. 2005, 89, 852-863. [CrossRef]

95. Chin, W.W.; Marcelin, B.L.; Newsted, P.R. A partial least squares latent variable modeling approach for measuring interaction effects: Results from a Monte Carlo simulation study and an electronic-mail emotion/adoption study. Inf. Syst. Res. 2003, 14, 189-217. [CrossRef]

96. Hami, N.; Muhamad, M.R.; Ebrahim, Z. The impact of sustainable manufacturing practices and innovation performance on economic sustainability. Procedia CIRP 2015, 26, 190-195. [CrossRef]

97. Singh, S.; Olugu, E.U.; Musa, S.N. Development of Sustainable Manufacturing Performance Evaluation Expert System for Small and Medium Enterprises. Procedia CIRP 2016, 40, 608-613. [CrossRef]

98. Yang, M.G.; Hong, P.; Modi, S.B. Impact of lean manufacturing and environmental management on business performance: An empirical study of manufacturing firms. Int. J. Prod. Econ. 2011, 129, 251-261. [CrossRef]

99. Nakano, M. A conceptual framework for sustainable manufacturing by focusing on risks in supply chains. IFIP Adv. Inf. Commun. Technol. 2010, 338, 160-167. 
100. Witjes, S.; Vermeulen, W.J.V.; Cramer, J.M. Exploring corporate sustainability integration into business activities. Experiences from 18 small and medium sized enterprises in the Netherlands. J. Clean. Prod. 2017, 153, 528-538. [CrossRef]

101. Revell, A.; Blackburn, R. The business case for sustainability? An examination of small firms in the UK's construction and restaurant sectors. Bus. Strategy Environ. 2007, 16, 404-420. [CrossRef]

102. Arora, S.; Cason, T.N. An Experiment in Voluntary Environmental Regulation: Participation in EPA's 33/50 Program. J. Environ. Econ. Manag. 1995, 28, 271-286. [CrossRef]

103. Hamann, R.; Smith, J.; Tashman, P.; Marshall, R.S. Why Do SMEs Go Green? An Analysis of Wine Firms in South Africa. Bus. Soc. 2017, 56, 23-56. [CrossRef]

104. Yu, J.; Bell, J.N.B. Building a sustainable business in China's small and medium-sized enterprises (SMEs). J. Environ. Assess. Policy Manag. 2007, 9, 19-43. [CrossRef]

105. Ren, S.; Li, X.; Yuan, B.; Li, D.; Chen, X. The effects of three types of environmental regulation on eco-efficiency: A cross-region analysis in China. J. Clean. Prod. 2018, 173, 245-255. [CrossRef] 